\title{
The longitudinal method: study of the change process in qualitative studies in management sciences
}

\author{
Nada Moufdi $^{1}$, and Ali Mansouri ${ }^{*}$ \\ ${ }^{1}$ Sidi Mohamed Ben Abdellah University, Morocco
}

\begin{abstract}
Considered as one of the tools available to the researcher to understand and analyze the process and course of phenomena, the longitudinal qualitative study remains, despite its importance, an ignored research protocol and is rarely used in management sciences. This contribution aims to provide clarification elements regarding the definition, typology, data collection methods and analysis of results in longitudinal qualitative research. It provides a helpful guide for conducting and reviewing longitudinal studies in these sciences.
\end{abstract}

\section{Introduction}

In management sciences, the development and use of qualitative longitudinal research are still limited. This method is particularly appropriate for understanding and examining processes through attention to context and specifics of each unit of analysis. It provides researchers with data, unlike cross-sectional methods, that allow them to understand the development and change of a phenomenon over time.

Thus, despite its importance, the longitudinal method still attracts growing interest from researchers in various disciplines. It remains a little-explored protocol raising many questions. Through this article, we aim to remedy this shortcoming while showing the existence of a particularism of this type of study concerning its data collection and analysis methods.

To do so, we will first shed light on the concept of "longitudinal research" to remove any conceptual ambiguity. Second, emphasis will be placed on the types of longitudinal studies available to researchers. Third, the methods of data collection and analysis are developed to clarify the process through which a qualitative longitudinal study is conducted.

\section{Longitudinal method: clarity of the concept and typologies}

\subsection{The longitudinal method: towards clarity of the concept}

\footnotetext{
${ }^{*}$ Corresponding author: mansouriali.apk@gmail.com
} 
Unlike the cross-sectional data collection method and analysis, the longitudinal method (also called panel data studies) is still an ambiguous tool with no consensus on its definition. Indeed, exploring the current state of development of the literature, the said method suffers from the scarcity [1] and non-existence of a definition shared by the entire scientific community.

Forgues, Vandangeon-Derumez and Garreau [2] describe as longitudinal any study that aims to analyze the evolution of different phenomena over time. Polyhart and Vandenberg [3] share this definition by suggesting that longitudinal research focuses on the study of change.

These definitions explicitly emphasize change and the importance of time in distinguishing this method from cross-sectional research. Indeed, longitudinal study is inseparable from time [2], which can be given an important role or be relegated to the background. "Table 1" illustrates the different roles that time can play in a longitudinal study.

Table 1. Place of time in longitudinal research

\begin{tabular}{|c|c|c|}
\hline Conception of time & Impact in research & Examples \\
\hline $\begin{array}{l}\text { Time is not important; it } \\
\text { only serves to classify the } \\
\text { observations. }\end{array}$ & $\begin{array}{l}\text { Time is relegated to the } \\
\text { background. The researcher } \\
\text { pursues a longitudinal study } \\
\text { and thus studies a } \\
\text { phenomenon over time, but } \\
\text { without attributing any } \\
\text { particular importance to it. } \\
\text { Time passes, that is all. }\end{array}$ & $\begin{array}{l}\text { Brown and Eisenhart [4] } \\
\text { study the continuous change } \\
\text { in six companies in the } \\
\text { computer industry without } \\
\text { regard to the duration or } \\
\text { period involved. }\end{array}$ \\
\hline $\begin{array}{l}\text { Time is an important } \\
\text { variable, operationalized } \\
\text { as duration. }\end{array}$ & $\begin{array}{l}\text { Time is a critical variable in } \\
\text { research. The time elapsed } \\
\text { between different events } \\
\text { must be carefully measured. }\end{array}$ & $\begin{array}{l}\text { Taylor, Audia and Gupta [5] } \\
\text { investigate whether the } \\
\text { length of time to wait before } \\
\text { being promoted impacts } \\
\text { manager involvement and } \\
\text { turnover. }\end{array}$ \\
\hline $\begin{array}{l}\text { Time is an important } \\
\text { variable, operationalized } \\
\text { in chronological form. }\end{array}$ & $\begin{array}{l}\text { Time has a common origin } \\
\text { to all observations. }\end{array}$ & $\begin{array}{l}\text { Pelz [6] studies the } \\
\text { sequence of innovation } \\
\text { processes by focusing on } \\
\text { the order of occurrence of } \\
\text { the different stages }\end{array}$ \\
\hline $\begin{array}{l}\text { Time is used to classify } \\
\text { individuals into cohorts - a } \\
\text { group of people who share } \\
\text { a common defining } \\
\text { characteristic or } \\
\text { experience over a defined } \\
\text { period- for comparison } \\
\text { purposes }\end{array}$ & $\begin{array}{l}\text { Time is an important } \\
\text { variable. It is used to } \\
\text { classify observations into } \\
\text { cohorts, i.e. groups that } \\
\text { have experienced the same } \\
\text { event (Forgues and al., [2]). }\end{array}$ & $\begin{array}{l}\text { Shaver, Mitchell, and } \\
\text { Yeung [7] test the impact of } \\
\text { experience on the survival } \\
\text { of foreign investment by } \\
\text { comparing cohorts based on } \\
\text { whether or not they were in } \\
\text { the United States in } 1986\end{array}$ \\
\hline $\begin{array}{l}\text { Time is seen as a social } \\
\text { construct }\end{array}$ & $\begin{array}{l}\text { Time is human time and the } \\
\text { time of life, intentions and } \\
\text { objectives. Time is } \\
\text { omnipresent; it is the time } \\
\text { felt by individuals. }\end{array}$ & $\begin{array}{l}\text { Orlikowski and Yates [8] } \\
\text { show how time (through } \\
\text { different temporal } \\
\text { structures) makes sense to } \\
\text { actors and conditions their } \\
\text { future actions. }\end{array}$ \\
\hline
\end{tabular}


In addition to time, longitudinal analyses are opposed to cross-sectional studies by the number of data collected; researchers in the field specify that collecting many waves of repeated measurements is essential to conduct a longitudinal study. This protocol enriches the analysis and interpretation of the results obtained by clarifying the change in a unit (organization, team, individual, etc.) overtime or the growth trajectory of that unit $[9,10]$.

The number of times the data were collected is still a point of divergence between researchers. As for Menard [11], longitudinal studies compare data between two distinct periods (the subjects are identical from one period to the next). This view is shared by Taris [12]. This author explains that longitudinal data are collected for the same research units on two or more occasions.

Polyhart and Vandenberg [3] considered this number to be insufficient for the following reasons: any change between time one and time 2 is by default linear (i.e., a straight line), which makes it impossible to determine the shape of that change over time (Rogosa, [13]); It is simply an increment of difference between two points in time, which makes it impossible for us to decide whether the change was smooth or delayed or whether it reached a plateau before changing again (Singer and Willett, [10]). Similarly, the two-period limitation on data collection confuses actual change with measurement error. Hence the need, according to the same authors, for a minimum of three (more than three is preferable) repeated observations on the same subject to increase the reliability of the study.

\subsection{Types of longitudinal studies}

Longitudinal studies can be conducted, according to Piper Deschenes [14], through one of four types: trend studies, panel designs, cohort studies and time-series designs. Each of these types is characterized by a sample group, study duration and several measures obtained.

In the first type - trend studies - the researcher examines the changes that a representative sample of a general population has experienced over time. This type is typically exemplified by Wish's [15] study that measured changes in the type and amount of drug use by arrestees over four quarters within a year and from one year to the next.

The second type of longitudinal study - panel designs - is characterized by the collection of repeated measures from the same sample at different points in time - the unit of analysis is tracked at specific intervals over a long period, often many years. Many researchers consider this design to be the best for actually determining changes over time, as it involves tracking the opinions of the same respondents over and over again.

Unlike these two methods, cohort studies involve studying the same population each time data are collected, even though the sample may differ from one period to another.

The final type of longitudinal study - time-series designs - involves a series of measurements at periodic intervals, usually to measure the impact of a specific change that occurs at some point during those measurements (Piper Deschenes, [14]). Longitudinal data resemble a time series when the same thing is measured over time. This type of study allows us, unlike the others mentioned above, to measure the overall change in the measure over time and not just measure the difference at the individual level.

The following table summarizes the points of similarity and difference between the four types of longitudinal studies. 
Table 2. Characteristics of longitudinal study types

\begin{tabular}{|c|l|l|l|l|}
\cline { 2 - 5 } \multicolumn{1}{c|}{} & Trend studies & Panel models & \multicolumn{1}{c|}{$\begin{array}{c}\text { Cohort } \\
\text { studies }\end{array}$} & $\begin{array}{c}\text { Time-series } \\
\text { models }\end{array}$ \\
\hline Sampled group & $\begin{array}{l}\text { The sample } \\
\text { may differ }\end{array}$ & Same sample & $\begin{array}{l}\text { The sample } \\
\text { may differ }\end{array}$ & Same sample \\
\hline $\begin{array}{c}\text { Duration of the } \\
\text { study }\end{array}$ & $\begin{array}{l}\text { Specific and } \\
\text { regular } \\
\text { intervals }\end{array}$ & $\begin{array}{l}\text { Specific and } \\
\text { regular } \\
\text { intervals }\end{array}$ & $\begin{array}{l}\text { Infrequent } \\
\text { intervals }\end{array}$ & $\begin{array}{l}\text { Specific and } \\
\text { regular } \\
\text { intervals }\end{array}$ \\
\hline $\begin{array}{c}\text { Number of } \\
\text { measures }\end{array}$ & $\begin{array}{l}\text { Repeated } \\
\text { measurements }\end{array}$ & $\begin{array}{l}\text { Repeated } \\
\text { measurements }\end{array}$ & $\begin{array}{l}\text { Repeated } \\
\text { measurements }\end{array}$ & $\begin{array}{l}\text { Series of } \\
\text { measurements }\end{array}$ \\
\hline
\end{tabular}

Source: The authors.

\section{Longitudinal qualitative research: data collection and analysis}

\subsection{Longitudinal data collection}

The researcher has two different methods of data collection to conduct a longitudinal study: the prospective method and the retrospective method. The former consists of studying the subjects selected over time, while in the latter, the study is conducted on the past behaviours of said subjects.

In qualitative research, prospective studies have more advantages than retrospective longitudinal designs. Indeed, in the latter, study subjects (interviewees...) may face memory recall problems or telescoping; individuals may not remember events accurately or attribute them to the wrong period.

However, despite the benefits of survey research, it has limitations that threaten the continuity and completion of the study; to conduct a prospective longitudinal study, it may be necessary to wait several years before analyzing the data collected. Similarly, long-term follow-up of individuals to obtain information is very costly. In some cases, the researcher cannot continue the prospective longitudinal research because of the death of the individuals under study or the loss of their collaborations over time-subjects may drop out of the study, resulting in a loss of data (often referred to as "attrition").

\subsection{Analysis of longitudinal qualitative data}

Today, qualitative methods are experiencing a significant resurgence of interest in the management sciences. Indeed, according to Elliott, Holland and Thomson [16], the limitations of quantitative methods and the criticism of positivism in the social sciences have led researchers to explore and make greater use of qualitative approaches. Qualitative approaches are particularly appropriate for understanding and examining processes through attention to context and particularity.

Longitudinal qualitative research, the focus of our work, is based on the study and interpretation of change over time and process in social contexts; it aims to understand the unfolding of a phenomenon based on three significant sets brought together in the course of the analysis: the context, the actions of individuals, and the temporal interconnection between activities (Pettigrew, [17]).

The analysis of longitudinal qualitative data mainly involves description, analysis and interpretation. At the description level, the researcher is supposed to produce a monograph 
of the process studied; this consists of writing its history in narrative form by describing it in detail. This monograph makes it possible to reconstruct the sequence of events.

The objective of this phase is to follow the evolution of the conceptual categories over time. To do this, Miles and Huberman [18] propose the use of a chronological matrix in which the researcher places the periods of the process (from 1 to $n$ ) in the columns and the categories of the analysis in line with the theoretical framework adopted (Forgues and al., [2]).

The second phase is devoted to explain how and why the changes occurred. The analysis of longitudinal qualitative data can aim to understand the changes of the same object over time or the emergence of a phenomenon over time.

For the first, the researcher aims to understand the modification of a phenomenon over time (Figure 1). These analyses are based on the assumption that a concept can take on different modalities. For example, the leadership style of a company can be paternalistic, laissez-faire, authoritarian, and so on.

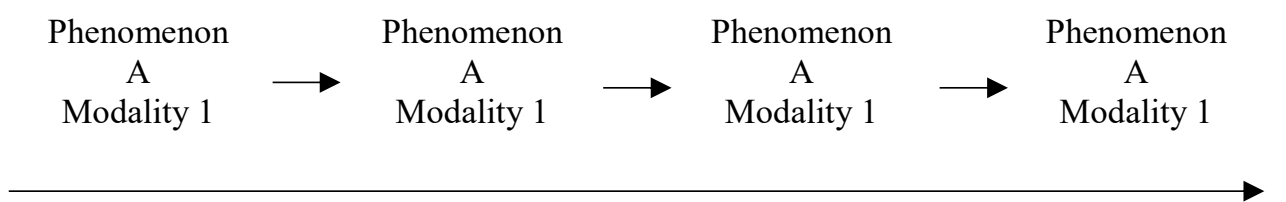

Fig. 1. Understanding how the phenomenon changes over time

Time Source: [2]

The second aim, as mentioned above, at understanding the construction of a phenomenon over time. It is a question, then, of analyzing how several mechanisms lead, through time, to the realization and construction of a phenomenon (Figure 2).

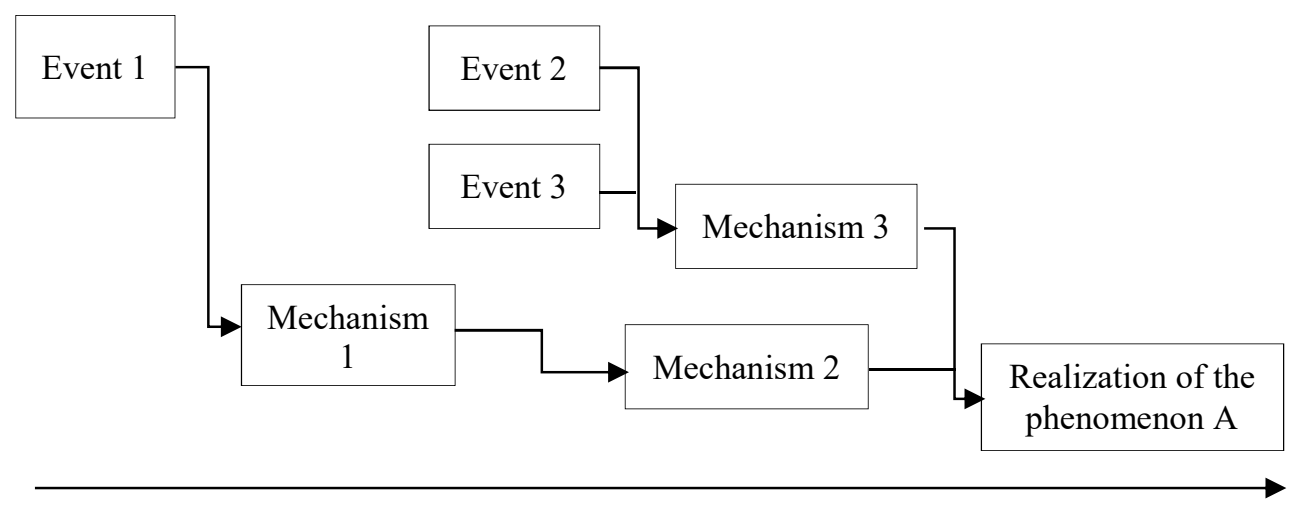

Time

Fig. 2. Understanding the culmination of a phenomenon over time Source: [18]

The final step in the analysis of longitudinal qualitative data is "interpretation". It allows us to explain the nature and meaning of the changes and to develop, in some cases, a theory that will enable the transfer of the results obtained to other implementation contexts. 


\section{Conclusion:}

Through the past developments, we have exposed the interest of using longitudinal qualitative research in management sciences. It consists of understanding a phenomenon by looking at how and why it evolves.

Our literature review identified four types of longitudinal studies - trend studies, panel designs, cohort studies, and time-series designs - each of which is characterized by a sample group, a study duration, and several measures obtained.

As for the data collection methods, the researcher is supposed to choose, besides the type of longitudinal study, between the prospective method and the retrospective method. Each of these methods has advantages and disadvantages that researchers must identify to mobilize the most suitable and appropriate one for their study. The analysis of these data involves description, analysis and interpretation.

However, despite the benefits mentioned above, the present method still faces a several significant challenges related to the design of qualitative research in management sciences, the most important of which are: the increased financial and temporal requirements associated with this approach and the risk of losing track of the units of analysis (individual, organization, team, and so on) over time.

\section{Bibliography:}

1. M. Wang, D. Beal, D. Chan, D, Newman, J. Vancouver, Vandenberg, longitudinal research: a panel discussion on conceptual issues, research design, and statistical techniques, in Work, Aging and Retirement, 3, 1-24 (2017)

2. B. Forgues, I. Vandangeon-Derumez, L. Garreau, Analyses longitudinals, in Thietart, 410-690 (2007)

3. R. Polyhart, R. Vandenberg, Longitudinal research: the theory, design, and analysis of change, in Journal of Management, 36 (2010)

4. S. Brown, K.Eisenhardt, The art of continuous change: linking complexity theory and time-paced evolution in relentlessly shifting organizations, in Administrative Science Quarterly, 42, 1-34 (1997)

5. M. Taylor, G. Audia, A. Gupta, The effect of lengthening job tenure on managers organizational commitment and turnover, Organization Science, 7, 632-648 (1996)

6. D. Pelz, Innovation complexity and the sequence of innovating stages, in Knowledge: Creation, Diffusion, Utilization, 6, 261-291 (1985)

7. J. Shaver, W. Mitchell, B. Yeung, The effect of own-firm and other firm experience on foreign direct investment survival in the united states, in Strategic Management, 18, 811824 (1997)

8. W. Orlikowski, J. Yates, It is about time: temporal structuring organizations, Organization Science, 13, 684-700 (2002)

9. K. Bollen, P. Curran, Latent curve models: a structural equation perspective, in Hoboken (2006)

10. J. Singer, J. Willett, Applied longitudinal data analysis, New York: Oxford University Press (2003)

11. S. Menard, Longitudinal research, Age university paper series on quantitative applications in the social sciences, Newbury Park, Sage (1991)

12. T. Taris, Longitudinal data analysis, London, UK: Sage publications (2000) 
13. D. Rogosa, Myths and methods: Myths about longitudinal research plus supplemental questions, in The analysis of change, 3-66 (1995)

14. E. Piper Deschenes, Longitudinal research designs, Measurement Issues in Criminology (1990)

15. E. Wish, Identification of drug-abusing offenders: a guide of practitioners, Prosecutors Perspective, 2-3 (1987)

16. J. Elliott, J, Holland, R. Thomson, Qualitative and Quantitative longitudinal research in Bickman, Handbook of social research methods, London/Thousand Oaks: Sage (2007)

17. A. Pettigrew, What is a processual analysis?, Scandinavian Journal of Management, 13, 337-348 (1997)

18. M. Miles, A. Huberman, Analyzing qualitative data: a sourcebook for new methods, Beverly Hills, Sage (1979) 